See discussions, stats, and author profiles for this publication at: https://www.researchgate.net/publication/345319166

\title{
Analyzing efficiency of optical and THz infrared thermography in nondestructive testing of GFRPs by using the Tanimoto criterion
}

Article in NDT \& E International · November 2020

DOI: 10.1016/.jndteint.2020.102383

\section{CITATIONS}

6 authors, including:

Alain Sommier

Institut de Mécanique et d'Ingénierie de Bordeaux

102 PUBLICATIONS 383 CITATIONS

SEE PROFILE

Vladimir Vavilov

Tomsk Polytechnic University

262 PUBLICATIONS 2,243 CITATIONS

SEE PROFILE

Some of the authors of this publication are also working on these related projects:

Project microscale View project

Project Application on $\mathrm{THZ}$ imaging View project
READS

88

Christophe Pradere

Institut de Mécanique et d'Ingénierie de Bordeaux

127 PUBLICATIONS 956 CITATIONS

SEE PROFILE 


\title{
Analyzing efficiency of optical and THz infrared thermography in nondestructive testing of GFRPs by using the Tanimoto criterion
}

\author{
A.O. Chulkov ${ }^{\text {a }}$, A. Sommier ${ }^{\text {b }}$, C. Pradere ${ }^{\text {b }}$, V.P. Vavilov ${ }^{\text {a, }}$, A.O. Siddiqui ${ }^{\text {c }}$, Y.L.V.D. Prasad ${ }^{\text {c }}$

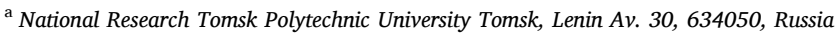 \\ ${ }^{\mathrm{b}}$ I2M UMR CNRS-ENSAM-UB 5295, Esplanade des arts et métiers, 33405, Talence CEDEX, France \\ ${ }^{c}$ Advanced Systems Laboratory, Kanchanbagh P.O, Hyderabad, 500058, Telangana, India
}

\section{A R T I C L E I N F O}

\section{Keywords:}

Infrared thermography

Terahertz imaging

GFRP

Tanimoto criterion

Nondestructive testing

\begin{abstract}
A B S T R A C T
This study has illustrated the potentials of optical and THz infrared thermography in the identification of inserts of different nature in glass fiber reinforced polymer. The inspection efficiency has been comparatively evaluated by applying the Tanimoto criterion. The best test procedure has proven to be one-sided stationary thermal nondestructive testing (TNDT) implementing optical heating with Xenon lamps (Tanimoto criterion 87\%). Close values of the Tanimoto criterion have been achieved by using the optical and THz line-scanning procedures. A more subjective evaluation of test procedures has been performed by comparing eight parameters of test performance. The line-scanning TNDT procedure implementing optical heating with halogen lamps seems to be optimal in practical applications.
\end{abstract}

\section{Introduction}

Techniques of nondestructive testing involve the analysis of some physical processes occurring in solids as a result of applied thermal stimulation [1-4]. The presence of hidden defects causes variations of a basic signal $\Delta S$, and from the theoretical point of view an optimal nondestructive testing (NDT) method should provide a maximum signal-to-noise ratio (SNR) $\Delta S / \sigma_{S}$, where $\sigma_{S}$ is the standard deviation of the signal constituting noise of different nature. From the practical point of view, the optimization of test procedures involves many other parameters, such as inspection rate, automation potentials, safety issues, etc. The use of the SNR concept is ubiquitous in NDT, but it is weakly related to visual perception of images formed by some NDT techniques. Therefore, some other comparison parameters have been proposed, such as the Tanimoto criterion [5-7].

In this study, we compare results of infrared (IR) thermographic and TeraHertz (THz) NDT of glass fiber reinforced plastic (GFRP) by using the Tanimoto criterion and analyzing heuristically some other characteristics of inspection performance. Our start point is that IR thermography is the acknowledged technique for detecting and evaluating discontinuities in GFRP in a one-sided test procedure [8-14], while the $\mathrm{THz}$ method is a promising newcomer in the field of NDT of composites
[15-18]. The comparison of these two methods is of interest in the aviation and aerospace industry where composites are successfully replacing metals.

\section{Test sample}

The $195 \times 195 \times 9 \mathrm{~mm}^{3}$ test sample made of GFRP contained 12 artificial defects with lateral size $10 \times 10$ and $20 \times 20 \mathrm{~mm}^{2}$ incorporated during sample manufacturing (see the photo of the sample and the scheme of defect location in Fig. 1). Defects were open air slits (D1-D4), foam inserts (D5, D7, D10, D12), epoxy resin inserts (D6, D8) and internal air gaps (D9, D11) located at the depths of 6.16 (D1, D4, D5, D6, D9, D12) and $4.95 \mathrm{~mm}$ (D2, D3, D7, D8, D10, D11). The thickness of all inserts was $0.64 \mathrm{~mm}$. The sample was painted with the acrylic black dye in order to increase the absorption coefficient up to 0.96 and diminish GFRP optical semi-transparence (the latter phenomenon might be essential when applying optical heating).

The reference sample has been supposed to simulate some typical defects which might appear in GFRP in manufacture and operation. However, it is worth noting that development of trust-worthy reference samples deserves a special investigation. Independently on a testing technique, defects of the same nature and size produce similar but not

\footnotetext{
* Corresponding author. Tomsk Polytechnic University, Savinykh St., 7, 634028, Tomsk, Russian Federation.

E-mail addresses: chulkovao@tpu.ru (A.O.Chulkov), alain.sommier@u-bordeaux.fr (A. Sommier), christophe.pradere@u-bordeaux.fr (C. Pradere), vavilov@tpu. ru (V.P. Vavilov), ahmedovaissiddiqui@asl.drdo.in (A.O. Siddiqui), ylvdprasad@gmail.com (Y.L.V.D. Prasad).
} 
identical signals because of a spread in planned defect parameters, in particular, if a resin is used in producing defects. This makes development of reference samples difficult.

\section{Infrared thermography}

The reference sample described above was tested by applying a couple of IR thermographic inspection techniques, namely, classical one- and two-sided "stationary" procedures using $2 \mathrm{~kW}$ halogen (Fig. 2a) and $2.2 \mathrm{~kJ}$ Xenon flash tubes (Fig. 2b), as well as a scanning procedure involving a $2 \mathrm{~kW}$ linear heater (Fig. 2c). Temperature distributions on the sample surface were recorded by using an Optris Pi450 $(382 \times 288$, 7-13 $\mu \mathrm{m})$ and FLIR SCX6900 $(640 \times 512,7-13 \mu \mathrm{m})$ IR imagers.

Results of one- and two-sided IR thermographic tests are presented in Fig. 3. The sample was exposed to optical heating for 10 and $20 \mathrm{~s}$ (in oneand two-sided test procedures), with the distance between the heater and the sample being $0.4 \mathrm{~m}$, and acquisition frequency - $10 \mathrm{~Hz}$. Note that, in one-sided procedures, the sample was tested on both front and rear sample surfaces. Test results were processed by applying the techniques of Principle Component Analysis (PCA) and Thermographic Signal Reconstruction (TSR) [19-25].

The one-sided test procedure applied to the front surface (A) allowed to detect all defects except the defect D1. Oppositely, the results obtained in the rear-surface test clearly showed the defect D1, which was the closest to the rear surface (B). By applying the two-sided test, one was able to detect all defects, however, the defects \#6 and \#8 (epoxy resin inserts) were characterized by fairly week signals.

The better results were demonstrated by having applied the linescanning procedure of thermal NDT (TNDT), Fig. 4, probably, due to a higher heating power and a more uniform heating pattern to compare to the stationary procedures. After having the sample passed the heating zone, its surface temperature was recorded at the cooling stage within the time period from 20 to $85 \mathrm{~s}$ by using two Optris IP450 IR cameras placed opposite to each other. Note that test parameters, such as the movement speed $(5 \mathrm{~mm} / \mathrm{s})$, acquisition frame rate $(5.8 \mathrm{~Hz})$ and the width of a single scanned line $(1.09 \mathrm{pixel} / \mathrm{mm})$ have been carefully chosen to ensure the synthesis of resulting IR images without under- and overlapping of scanned lines. One more test was performed by reducing the heating time up to $5 \mathrm{~s}$ and respectively increasing the movement speed up to $10 \mathrm{~mm} / \mathrm{s}$ (the frame rate was adjusted to $11.6 \mathrm{~Hz}$ ). The corresponding test results are presented in Fig. $4 \mathrm{c}$ and $\mathrm{d}$.

Fig. 5 shows the results obtained by applying the flash test procedure (two 2.2. kJ Xenon flash tubes). The temperature distributions were recorded by means of a FLIR x6900sc IR imager for $200 \mathrm{~s}$ with the acquisition rate of $50 \mathrm{~Hz}$. The best results have been achieved by analyzing IR image sequences within particular time intervals representing best observation times by the parameter of temperature contrast
$C=\Delta T / T_{n d}$, where $\Delta T$ is the differential temperature signal in a defect area, and $T_{n d}$ is the reference non-defect temperature (see Fig. 5a). The evolutions of the contrast have shown that the best observation times are from 20 to $100 \mathrm{~s}$, and the most defects are characterized by the "classical" behavior of $\Delta T$ and $C$ : the temperature signals over low-conductive defects reach maximums at particular times and then drop down. Oppositely, the defects D10 and D12 produced negative temperature signals and contrasts but of lower amplitudes (see the curves for D10 and D12 in Fig. 5a). Obviously, higher temperature signals appear over larger defects or those of whose thermal resistance strongly differs from the host material. To process IR images by applying the PCA technique, the 40-100 s interval has been used to enhance the visibility of the defects characterized by weak temperature signals.

The PCA approach has allowed identifying from 9 to 12 defects depending on a surface tested and a chosen PCA component. Similar results were obtained by using the TSR technique (Fig. 6).

The characterization of defect depth $h[\mathrm{~m}]$ and thermal resistance $R_{d}$ $=d / K_{d}$, where $d$ is the defect thickness [m], and $K_{d}$ is the defect conductivity $\left[\mathrm{W} \cdot \mathrm{m}^{-1} \cdot \mathrm{K}^{-1}\right]$, has been performed by using the inversion formulas obtained by solving a problem of heat conduction in a threelayer plate subjected to square-pulse heating. These formulas involve polynomial functions including experimental parameters [26]:

$$
\begin{aligned}
& h[m]=0.708\left[a\left(\tau_{m}-\tau_{h}\right)\right]^{0.456}\left(1-\frac{K_{d}}{K}\right)^{0.285}\left(\frac{L}{K}\right)^{0.0536} F_{h}^{0.0523} C^{-0.151}, \\
& R_{d}\left[m^{2} K W^{-1}\right]=4.368\left[a\left(\tau_{m}-\tau_{h}\right)\right]^{0.343}\left(1-\frac{K_{d}}{K}\right)^{1.265}\left(\frac{L}{K}\right)^{0.286} F o_{h}^{-0.0530} C^{0.426}
\end{aligned}
$$

Here $a\left[\mathrm{~m}^{2} \mathrm{~s}^{-1}\right]$ is the material thermal diffusivity of the material, $\tau_{m}$ [s] is the best observation time for a particular defect, $\tau_{h}[\mathrm{~s}]$ is the heating time, $L[\mathrm{~m}]$ is the sample thickness, $K\left[\mathrm{Wm}^{-1} \mathrm{~K}^{-1}\right]$ is the material thermal conductivity, $F_{h}=a \tau_{h} L^{-2}$ is the dimensionless Fourier number, and $C$ is the dimensionless running temperature contrast. The inversion formulas above could be précised for a narrower range of materials by choosing more carefully the numerical coefficients. The practical experience of using these equations has shown that the accuracy in determining $h$ is about $15-30 \%$ for different types of composites, while for $R_{d}$ the accuracy drops down to $40-60 \%$. The characterization algorithm described above is simple and robust allowing producing images of defect depth ("depthgrams") and thermal resistance. It should be also noted that the applied algorithm and formula were derived for air-filled defects, therefore, their validity in application to resin- and foam-filled defects is questionable.

To apply Eq. (1), each sequence of raw IR images was converted into the corresponding sequence of images representing evolution of contrast $C$. An example of choosing a reference area for determining $C$ is

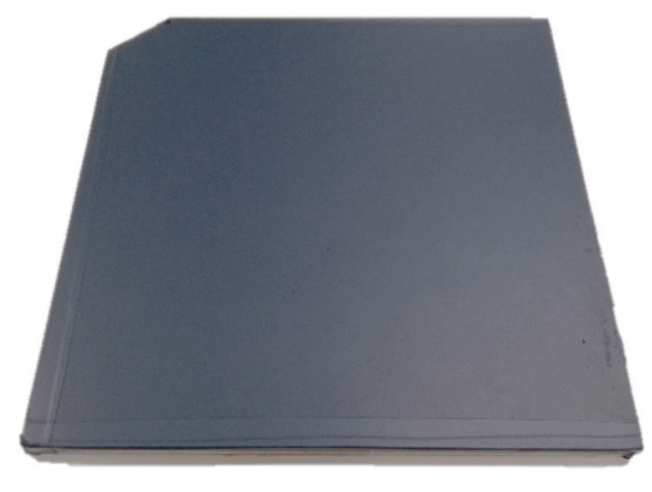

a)

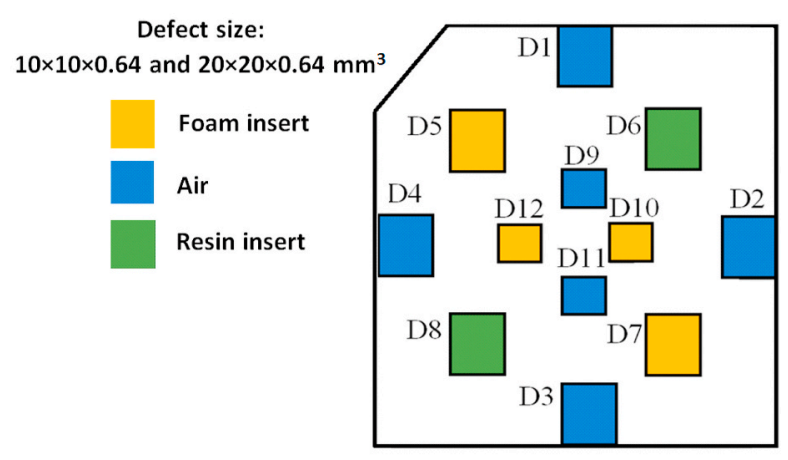

b)

Fig. 1. Photo of black-painted test sample (a) and scheme of defects (b). 


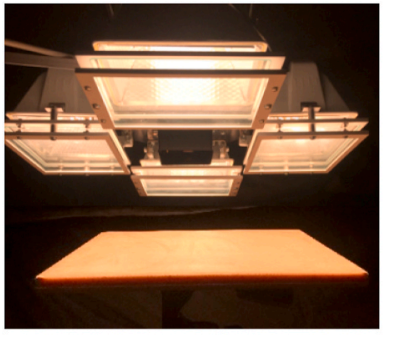

a)

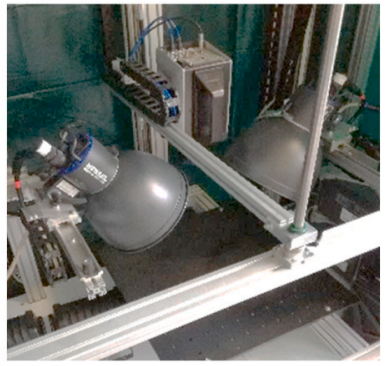

b)

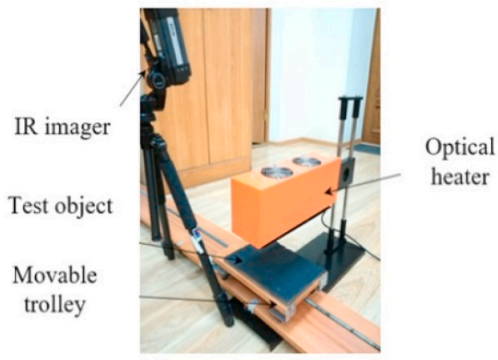

c)

Fig. 2. Experimental IR thermographic setups with halogen lamps (a), Xenon flash tubes (b) and line-scanning implementation (c).

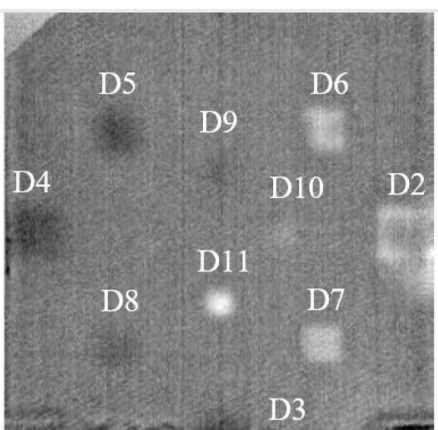

a)

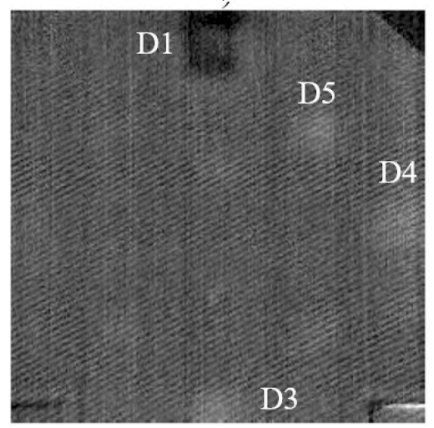

c)

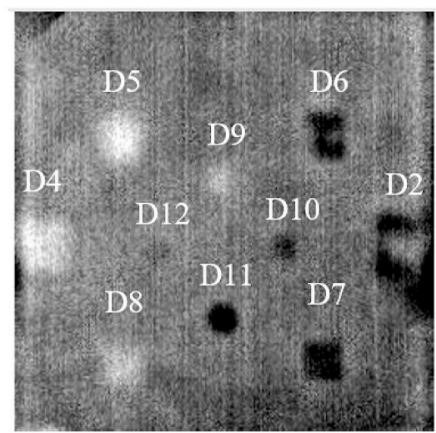

b)

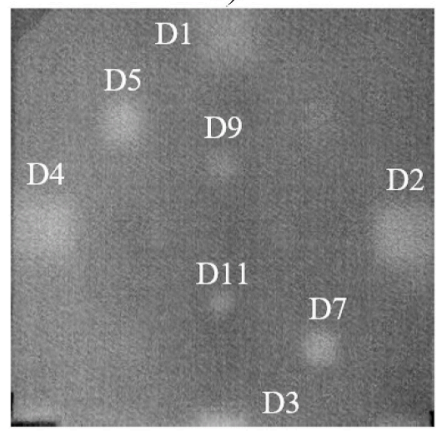

d)

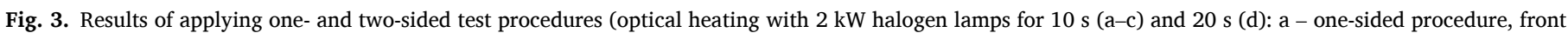

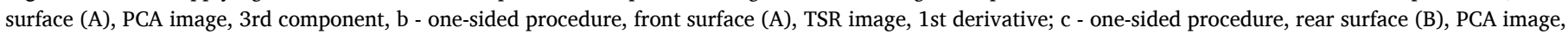
3rd component, d - two-sided procedure, front surface (A), PCA image, 1st component.

indicated in red in Fig. 5b. Next, the $C$-sequences were processed to calculate the images of the maximum running contrast $C_{m}$ (maxigrams) and the images of the best observation time $\tau_{m}$ (timegrams), as shown in Fig. 7 a, b for the subsequent calculation of $h$ and $R_{d}$. Note that Eq. (1) is valid if $C_{m}$ values occur after the heat pulse, i.e. $\tau_{m}>\tau_{h}$.

The depthgram in Fig. $7 \mathrm{c}$ shows the depths of particular defects. The accuracy of evaluated values from 6 to $20 \%$ was confirmed by measuring depth of open air slits \#1, 2 and 4 (defect \#3 was not evaluated because of the high thermal noise caused by a surface sticker).

The image of defect thermal resistance in Fig. $7 \mathrm{~d}$ shows all defects in more or less the same color, however, the defects \#6 and \#8 (resin inserts) have lower $R_{d}$ value. The pixel values in the defect areas \#2, 4, 5, 7, 9 and 11 correspond to $R_{d} \sim 0.015 \mathrm{~m}^{2} \mathrm{~K}^{\cdot \mathrm{W}^{-1}}$, and for defects \#6 and \#8 $R_{d} \sim 0.032 \mathrm{~m}^{2} \mathrm{~K} \cdot \mathrm{W}^{-1}$. Respectively, the above-mentioned values produce the following estimates of defect thickness: $d=8.5 \mathrm{~mm}$ if to assume that air conductivity in thin gaps is $0.07 \mathrm{~m}^{2} \mathrm{~K} \cdot \mathrm{W}^{-1}$, and $d=1.2$ $\mathrm{mm}$ if to assume that resin conductivity is $0.5 \mathrm{~m}^{2} \mathrm{~K} \cdot \mathrm{W}^{-1}$.

It is worth noting that the images in Fig. $7 \mathrm{c}$ and $\mathrm{d}$ have been produced with an amplitude threshold by $C$ values of $10 \%$ and $25 \%$ respectively. This has allowed obtaining clear images of defect indications while the non-defect areas were characterized by the constant values of $h=9 \mathrm{~mm}$ and $R_{d}=0$ respectively.

To visually demonstrate how defects are located within the sample, the algorithm of dynamic thermal tomography (DTT) was applied (see Fig. 8) [27-33]. In fact, each thermal tomogram shows distribution of $\tau_{m}$ times in a particular interval (with the introduced threshold of $1.2 \%$ by $\tau_{m}$ ). The DTT algorithm, like the defect characterization algorithm, requires selecting a reference point, and it is based on the analysis of the corresponding timegrams. By changing time intervals in a timegram, one can "slice" a test sample thanks to the fact that deeper layers are characterized by increasing time delays. Fig. $8 \mathrm{a}$ and $\mathrm{b}$ presents the layers (depth intervals) for two groups of defects: 1.5-3 mm with defects \#2, 6, 7,11 , and 3-5 mm with defects \#1, 3, 4, 5, 8, 9. Fig. $8 \mathrm{c}$-k illustrate the slicing of the sample with the depth step of $0.5 \mathrm{~mm}$. Respectively, Fig. 8 (1) shows the reconstruction of the sample performed by using the DTT algorithm.

\section{Terahertz imaging}

The THz imaging of the sample was fulfilled by using the two 


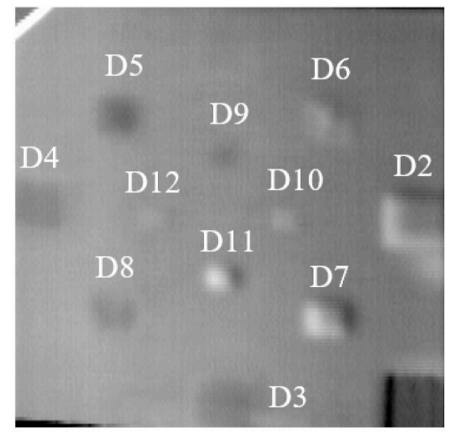

a)

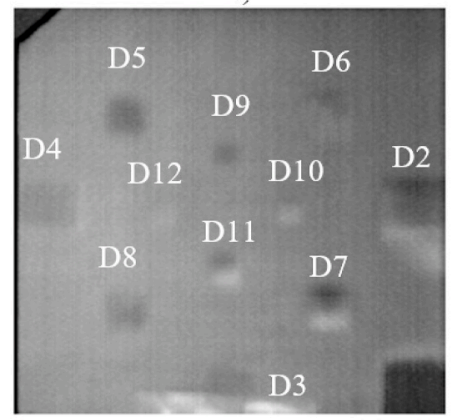

c)

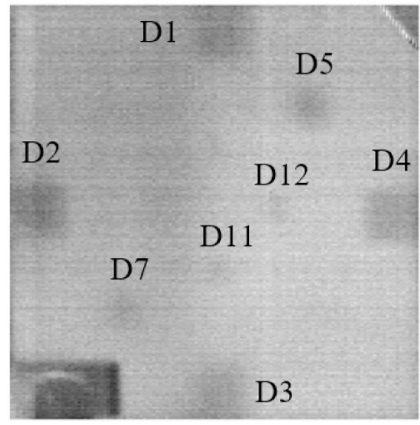

b)

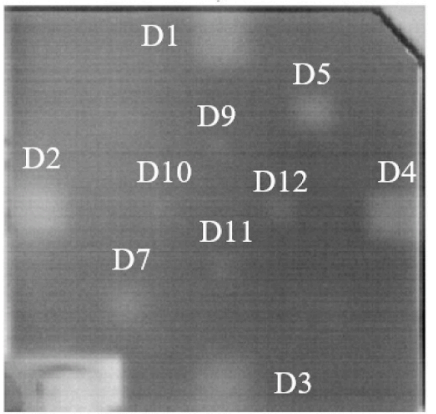

d)

Fig. 4. Test results obtained by using the scanning TNDT procedure (PCA images): a- front surface (A), heating duration $10 \mathrm{~s}$, movement speed $5 \mathrm{~mm} / \mathrm{s}$, frame rate $5.8 \mathrm{~Hz}, \mathrm{~b}$ - same as a), rear surface (B), c - front surface (A), heating duration $5 \mathrm{~s}$, movement speed $10 \mathrm{~mm} / \mathrm{s}$, frame rate $12 \mathrm{~Hz}, \mathrm{~d}-\mathrm{same}$ as c), rear surface (B).

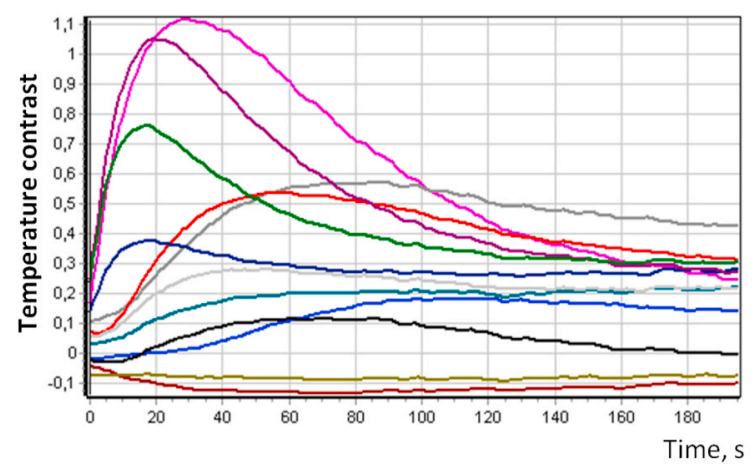

a)

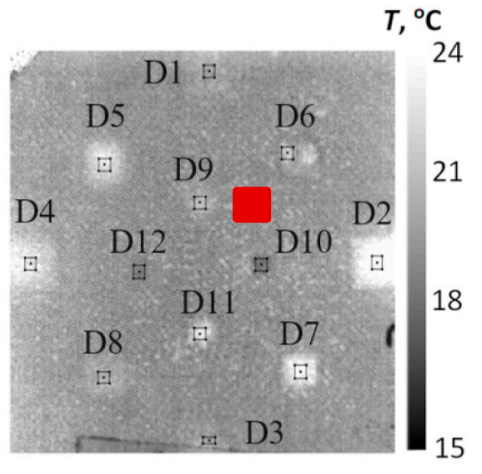

b)

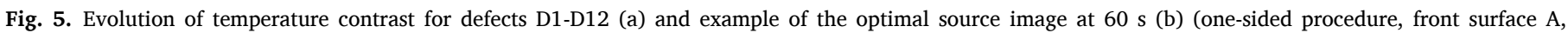
flash heating).

techniques: imaging scanning (Fig. 9a) and line-scanning (Fig. 9b). Both techniques were implemented in the transmission (two-sided) mode.

In the imaging scanning procedure, a THz source based on a Gunn diode with the power of $400 \mathrm{~mW}$ and frequency of $110 \mathrm{GHz}$ has been used. A set of Teflon lenses has been applied to focus the source beam into the spot with the diameter of $15 \mathrm{~mm}$ on the sample surface. To increase the SNR and image quality (spatial resolution and sensitivity), the scan of the sample was performed by a $3 \times 3 \mathrm{~mm}$ grid using a twocoordinate linear-motion system, and all scanned points overlapped each other by $10 \%$. The $\mathrm{THz}$ beam was partially absorbed while passing through the sample and totally absorbed by the Therathermal converter (TTC) $[34,35]$. The TTC temperature change was monitored with a FLIR SC7500 camera (frame rate $200 \mathrm{~Hz}$, resolution $40 \times 35$ pixels). Note that each point on the sample surface was exposed to $\mathrm{THz}$ irradiation for $8 \mathrm{~s}$ including 8 periods of saturation and relaxation of the TTC. The optimum time for observing each point $(8 \mathrm{~s})$ was evaluated by modeling absorption in a semitransparent body. During 7 of 8 periods, the temperature of the TTC reached stability, and temperature recording was performed in the 8th period. Fig. 10 explains the behavior of the TTC temperature signal during scanning.

At each scanned point, the temperature values were averaged in time by applying a moving filter. Some examples of resulting images are shown in Fig. 11.

It is important noting that the imaging scanning method took $12 \mathrm{~h}$ to scan the whole sample and allowed to detect from 8 to 10 defects depending on the processing procedure. It is interesting that some defects, such as \#6, \#8, \#9 and \#11, which are thin "inserts" of resin and air, can hardly be detected. This can be explained by the low difference in absorption coefficients of the inserts and sample material. The defects $\# 5$, \#7, \#10 and \#12 which are inserts of foam are characterized by the transparence close to GFRP, but these defects can easily be detected due to clearly visible borders apparently filled with air. The defects \#1-4 


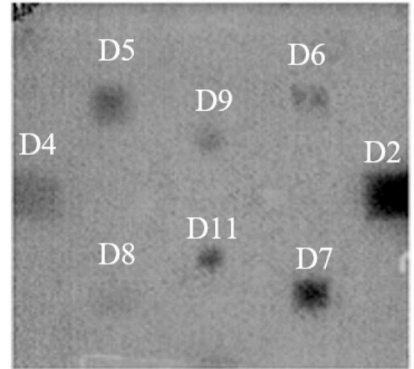

a)

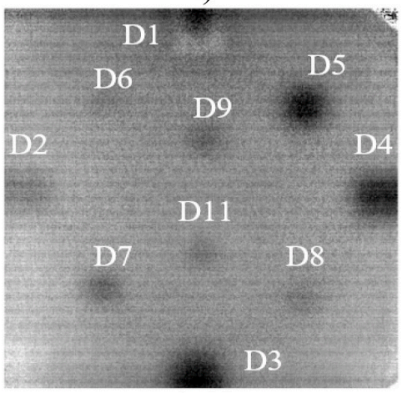

c)

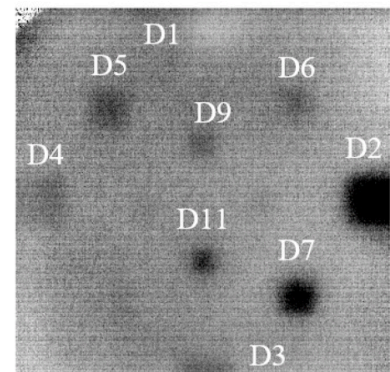

b)

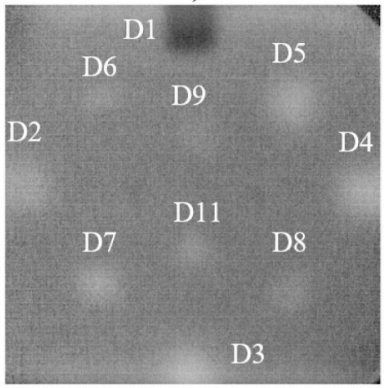

d)

Fig. 6. Results obtained by using flash heating in one-sided (a, b) and two-sided (c, d) test procedures: a - front surface (A), PCA image, 1st component, b - front surface (A), TSR image, 1st derivative, c - rear surface (B), PCA image, 2nd component, $d$ - rear surface (B), TSR image, 1st derivative.

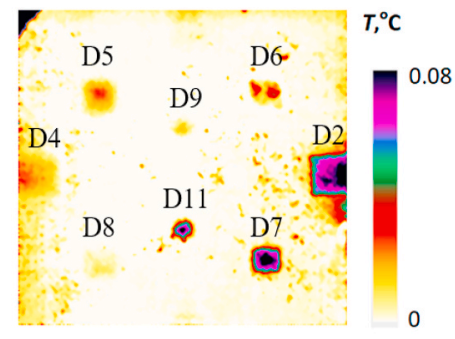

a)

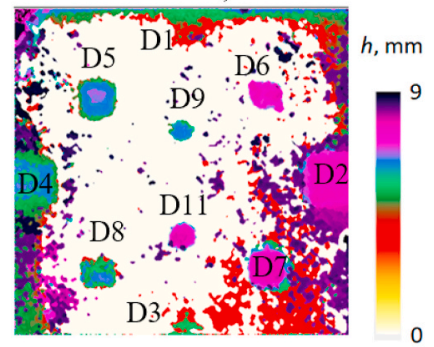

c)

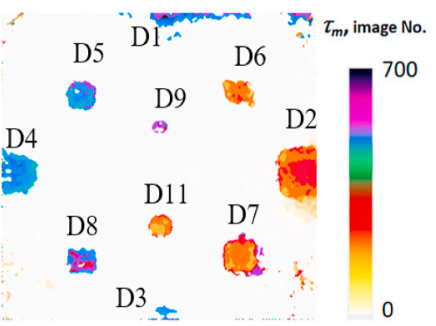

b)

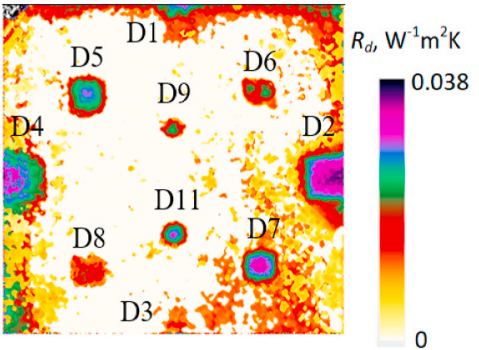

d)

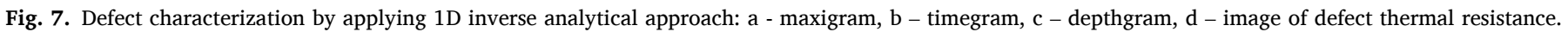

have lower absorption coefficient corresponding to air.

The results obtained by using the line-scanning method look less noisy and more sensitive to the structure of the sample, probably, due to a higher resolution of the transducer. The scanning was fulfilled by using a Terasense Sub-Thz imaging system. The sample was moving by means of a line-motion system with the speed of $15 \mathrm{~mm} / \mathrm{s}$. The system resolution along the detector direction was $0.68 \mathrm{pixel} / \mathrm{mm}$, and in the perpendicular direction - 33 pixel/mm ( THz pulse frequency $500 \mathrm{~Hz}$ ), see the result of scanning in Fig. 12.

One more drawback of Terahertz NDT is the difficulty to evaluate defect depth in the transmission inspection mode, therefore, in this study, only defect detection potentials of Terahertz NDT have been compared with results of classical TNDT.

\section{Evaluating inspection performance (Tanimoto criterion)}

As mentioned above, visual perception of test results is undoubtedly important in IR thermography. For example, reference (defect free) areas are identified by the operator who is guided by a certain list of pattern recognition rules. In this study, the set of test images (Figs. 3b, 4c and $4 d, 6 b, 6 d, 11 a, 12)$ taken by the authors as optimal were analyzed by 10 respondents who were familiar with basic principles of TNDT but not with the particular reference sample. The images were supplied in a random orientation in order to reduce the influence of the surface marker on defect identification. IR thermographic results have been analyzed in the grey-tone palette while the THz images were presented in the palette called "Summer". In fact, it has been shown elsewhere that 


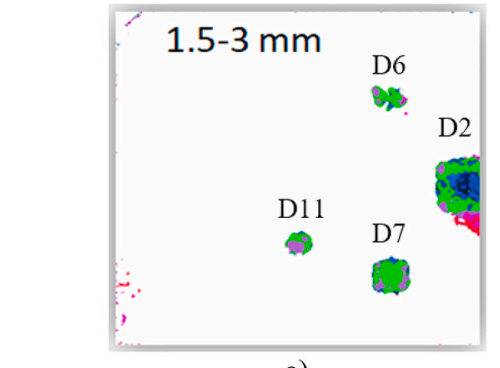

a)

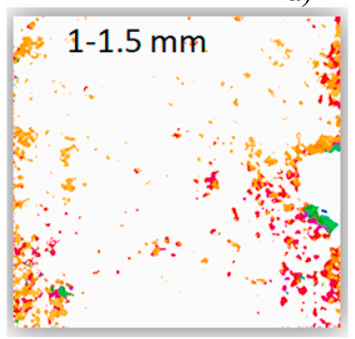

c)

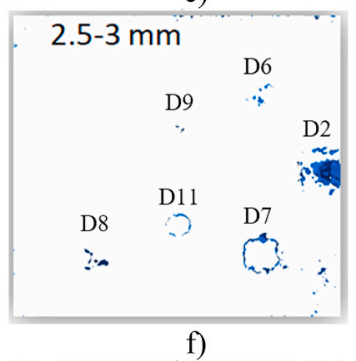

4-4.5 mm

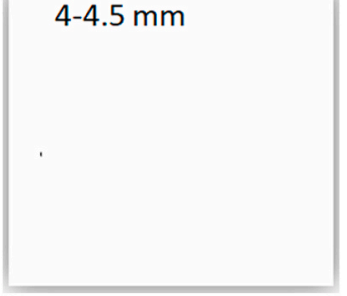

i)

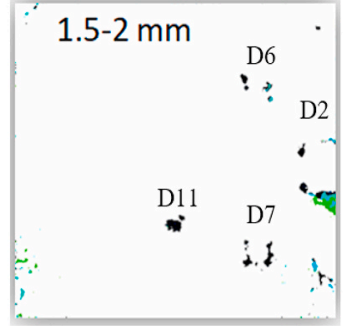

d)

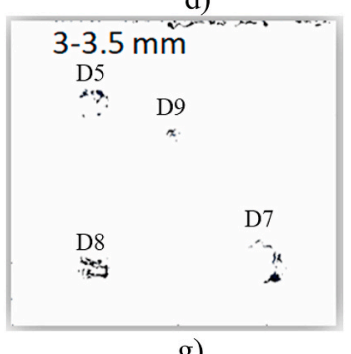

\section{g)}

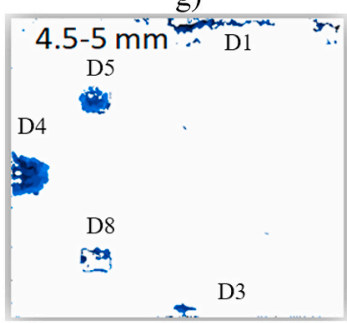

j)

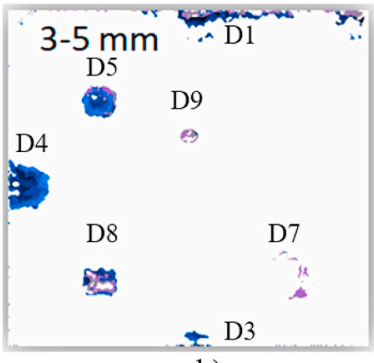

b)

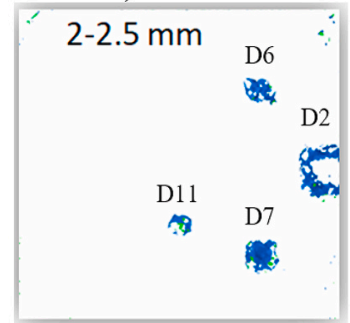

e)

$3.5-4 \mathrm{~mm}$

D5

D9

(3)

D8

r.

h)

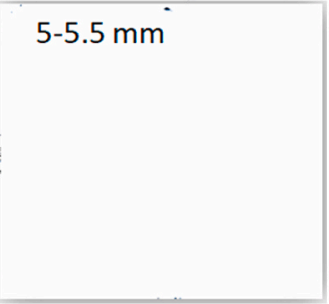

k)

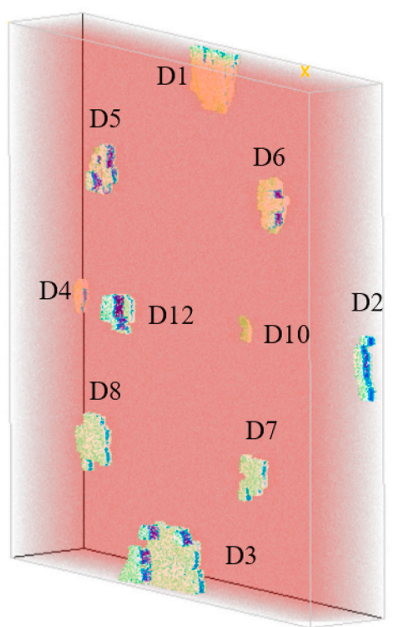

1)

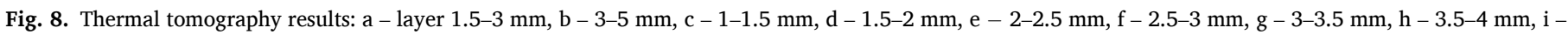
4-4.5 mm, j - 4.5-5 mm, k - 5-6.5 mm, l-3D reconstruction. 


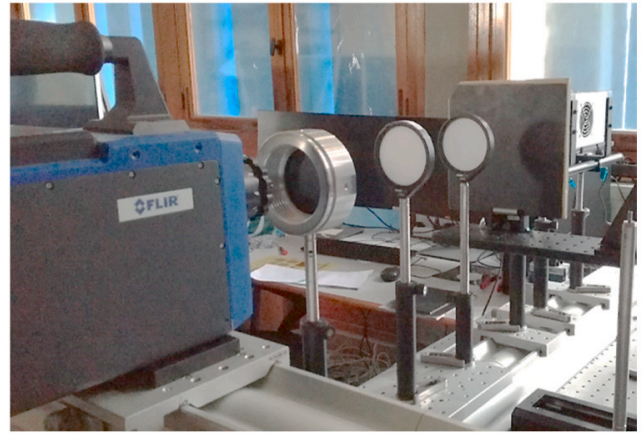

a)

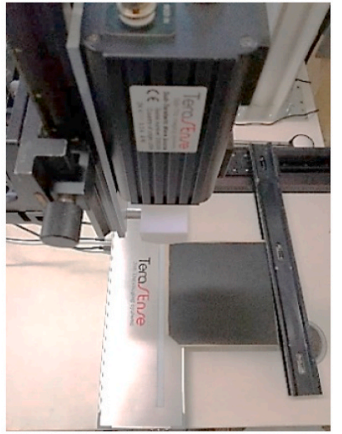

b)

Fig. 9. Experimental setups for THz imaging in transmission mode: a - imaging scanning procedure, $\mathrm{b}$ - line-scanning procedure.

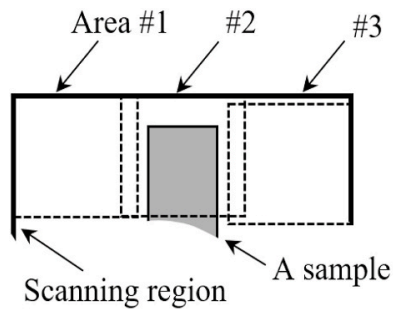

a)

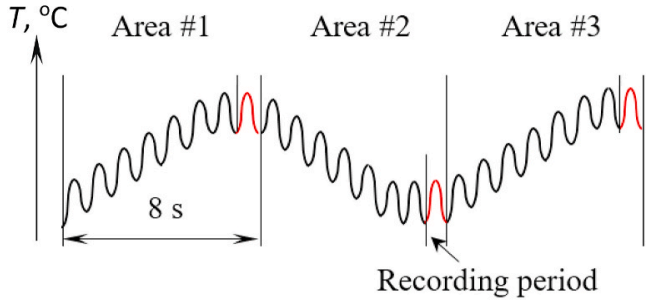

b)

Fig. 10. Point-by-point scanning THz technique: a - scanning scheme, b - TTC temperature evolution (saturated THz signal).

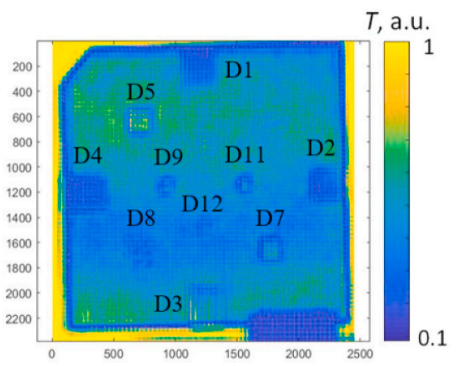

a)

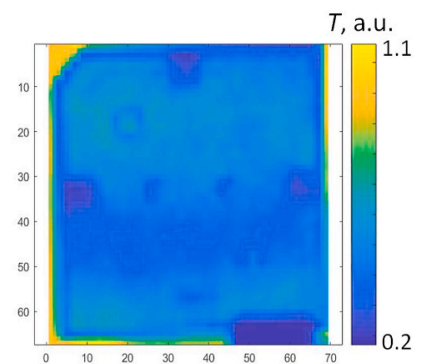

b)

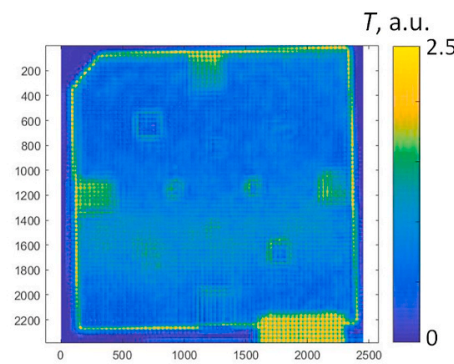

c)

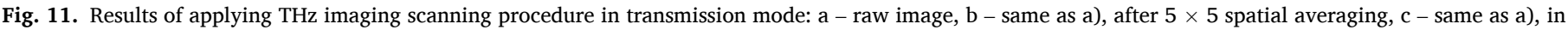
logarithmic scale.

the presentation of test results in different colors weakly influences on the interpretation of TNDT images [2].

Each respondent indicated the areas assumed to represent the defects, and this led to the appearance of some missed and false indications (see the examples of defect recognition in Fig. 13). The identification results were processed and averaged by 10 respondents by using the Tanimoto criterion $[1]$ :

$T C=\frac{N_{r . d .}-N_{m . d .}}{N_{r . d .}+N_{f . d .}}$

where $N_{r . d}, N_{m . d} ., N_{f . d}$. are the numbers of real, missed and false defects detected by an operator in the image analyzed $\left(N_{r . d},=12\right.$ in this case). The interesting feature of the Tanimoto criterion is that it combines missed and false defects.

The $T C$ values are presented in Table 1 to illustrate that, in general, the most efficient has been the TNDT procedure involving the TSR method of data processing (Fig. $6 \mathrm{~d}$ ) which provided $T C=0.87$, while the lowest $T C=0.72$ corresponded to the raw THz image (Fig. 11a). It is interesting to note that the lowest discrepancy in defect identification $(\sigma$ $=0.05$ ) was observed when the respondents analyzed the PCA images obtained by applying optical heating for $5 \mathrm{~s}$. Another remark of interest is that the analyzed test procedures have been characterized by the relatively low numbers of false defects, even if TNDT is typically considered as a fairly noisy inspection technique. In fact, the highest values of TC correlated well with the highest number of the defects correctly identified by the respondents.

However, the general performance of NDT techniques cannot be reduced to a single parameter, such as $S N R$ or TC. A quantitative evaluation is difficult because the value of specific parameters in making correct defect determinations depends on inspection requirements, inspection purpose, etc., even though the most important parameter of NDT systems in some applications may be credibility. Table 2 evaluates the technical performance of several inspection techniques according to the following parameters: 1) value of the Tanimoto criterion; 2) inspection rate in $\mathrm{m}^{2} \mathrm{hr}^{-1} ; 3$ ) ability to characterize defects (evaluating defect size and depth); 4) ability to detect an insert material (air, resin, foam, etc.); 5) minimum detectable defect size; 6) unit test area; 7) suitability for one- or two-sided testing, or both; 8) inspection complexity. Note that the analysis of the relationship between true lateral sizes of defects and their surface "footprints" by means of each 


\section{$T$, a.u.}

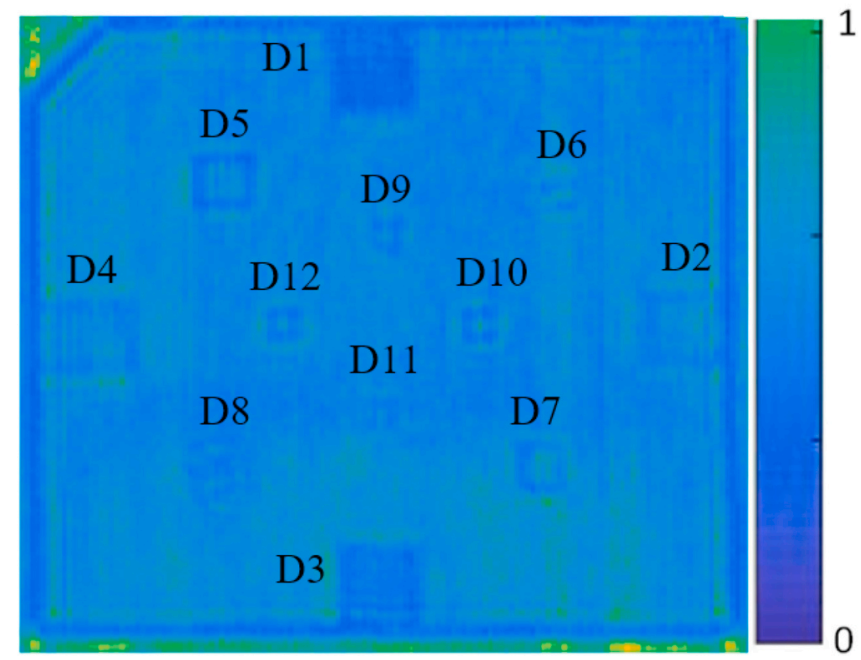

Fig. 12. Terahertz line-scanning results. used NDT technique has been beyond the scope of this research. It is supposed that the transmission Terahertz technique may provide the most clear defect indications, but TNDT procedures accompanied by lateral heat diffusion also allow determining defect lateral dimensions with the accuracy better than $10 \%$.

Obviously, the data in Table 2 is subjective, but it illustrates the concept for the test case in this study. It is recognized that a high inspection rate is a great advantage of TNDT compared to many other techniques. For example, according to Table 2, the highest inspection rate $\left(2.11 \mathrm{~m}^{2} \mathrm{~h}^{-1}\right)$ is achieved by a line-scanning procedure using halogen lamps, and this technique provides reasonable performance based on other performance parameters. Note that THz imaging is a relatively new NDT method, and one may expect its performance to improve in the near future.

\section{Conclusion}

This study has illustrated the potentials of optical and THz inspection in the identification of inserts of different nature in GFRP composite. The efficiency of five inspection procedures has been comparatively evaluated by applying the Tanimoto criterion which combines missed and false defects. With the highest possible value of this criterion equal to $100 \%$, the best test procedure has been one-sided "stationary" TNDT

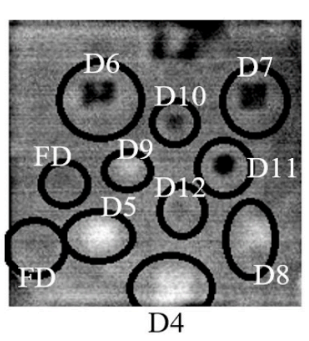

a)

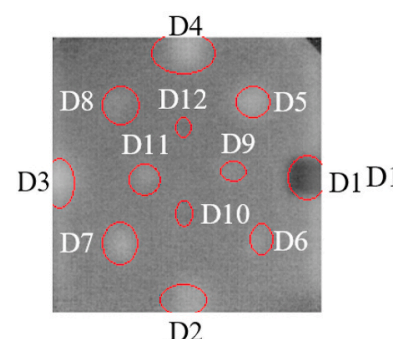

e)

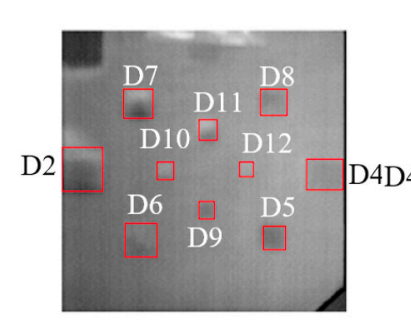

b)

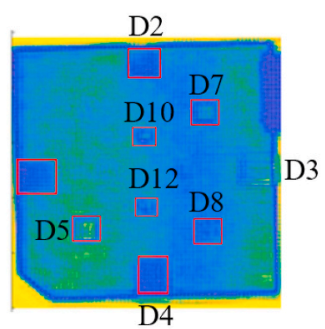

f)

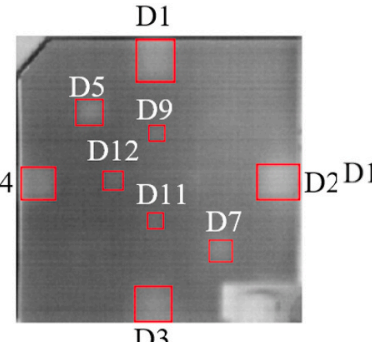

c)

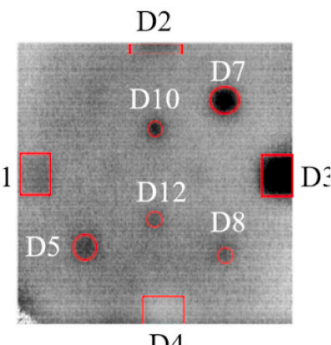

D4

d)

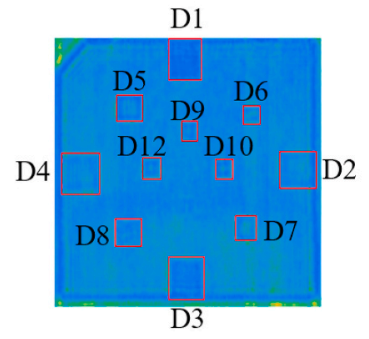

g)

Fig. 13. Analyzing test results by Tanimoto criterion: a - optical stationary heating, one-sided procedure, front surface, TSR, 1st derivative (Fig. 3b), b - optical linescanning heating, front surface (Fig. 4c), c - optical line-scanning heating, rear surface (Fig. 4d) d - flash heating, front surface, TSR, 1st derivative (Fig. 6b), e - flash heating, rear surface, TSR, 1st derivative (Fig. 6d), f - THz point-by-point scanning, Fig. 11a, g - THz line-scanning, Fig. 12.

Table 1

Test results by Tanimoto criterion.

\begin{tabular}{|c|c|c|c|c|c|c|c|}
\hline Image & $\begin{array}{l}\text { Optical stationary heating, } \\
\text { one-sided procedure, front } \\
\text { surface, TSR, 1st derivative ( } \\
\text { Fig. 3b) }\end{array}$ & $\begin{array}{l}\text { Optical line- } \\
\text { scanning heating, } \\
\text { front surface, ( } \\
\text { Fig. 4c) }\end{array}$ & $\begin{array}{l}\text { Optical line- } \\
\text { scanning heating, } \\
\text { rear surface ( } \\
\text { Fig. 4d) }\end{array}$ & $\begin{array}{l}\text { Flash heating, front } \\
\text { surface, TSR, 1st } \\
\text { derivative (Fig. 6b) }\end{array}$ & $\begin{array}{l}\text { Flash heating, rear } \\
\text { surface, TSR, 1st } \\
\text { derivative (Fig. 6d) }\end{array}$ & $\begin{array}{l}\text { THz point-by- } \\
\text { point scanning, } \\
\text { Fig. 11a }\end{array}$ & $\begin{array}{l}\text { THz line- } \\
\text { scanning, } \\
\text { Fig. } 12\end{array}$ \\
\hline$N_{\text {c.d. }}{ }^{\mathrm{a}}$ & 9,9 & 10,4 & 9 & 8,9 & 10,4 & 8,7 & 9,8 \\
\hline$N_{m \cdot d}$ & 2,1 & 1,6 & 3 & 3,1 & 1,6 & 3,3 & 2,2 \\
\hline$N_{f . d .}$ & 0,5 & 0,1 & 0 & 0,2 & 0 & 0,1 & 0 \\
\hline$T C \pm \sigma^{\mathrm{b}}$ & $0,80 \pm 0,09$ & $0,86 \pm 0,05$ & $0,75 \pm 0,11$ & $0,73 \pm 0,08$ & $0,87 \pm 0,10$ & $0,72 \pm 0,08$ & $0,82 \pm 0,19$ \\
\hline
\end{tabular}

${ }^{\text {a }} N_{c . d}$ is the number of true defects correctly identified by a respondent $\left(N_{c . d}=N_{r . d^{-}} N_{m . d}\right.$. $)$.

${ }^{\mathrm{b}} \sigma$ is the standard deviation of $T C$ values determined by 10 respondents. 
Table 2

Evaluating performance of TNDT and THz NDT test results.

\begin{tabular}{|c|c|c|c|c|c|}
\hline \multirow[t]{2}{*}{ Performance parameter } & \multicolumn{5}{|l|}{ Test method } \\
\hline & $\begin{array}{l}\text { Optical stationary heating } \\
\text { (halogen lamps) }\end{array}$ & $\begin{array}{l}\text { Optical heating (line } \\
\text { scanning, halogen lamps) }\end{array}$ & $\begin{array}{l}\text { Optical stationary heating } \\
\text { (Xenon lamps) }\end{array}$ & $\begin{array}{l}\text { THz technique (point-by- } \\
\text { point scanning) }\end{array}$ & $\begin{array}{l}\text { THz technique (line } \\
\text { scanning) }\end{array}$ \\
\hline Tanimoto criterion & 0.80 & 0.86 & 0.87 & 0.72 & 0.82 \\
\hline Inspection rate, $\mathrm{m}^{2} \cdot \mathrm{hr}^{-1}$ & 0.76 & 2.11 & 0.76 & 0.0048 & 7.61 \\
\hline $\begin{array}{l}\text { Ability to characterize defect } \\
\text { size/depth/thickness }\end{array}$ & $+/+/+$ & $+{ }^{\mathrm{a}} /+^{\mathrm{a}} /+$ & $+/+/+$ & $+/-/+$ & $+/-/+$ \\
\hline Ability to detect insert material & + & + & + & $+{ }^{\mathrm{b}}$ & $+{ }^{\mathrm{b}}$ \\
\hline $\begin{array}{l}\text { Minimal detectable defect size, } \\
\text { mm }\end{array}$ & $10 \times 10$ & $10 \times 10$ & $10 \times 10$ & $10 \times 10$ & $10 \times 10$ \\
\hline Unit test area, mm & $350 \times 350$ & $300 \times 100$ & $300 \times 300$ & $4 \times 4$ & $300 \times 30$ \\
\hline $\begin{array}{l}\text { Suitability for one- and two- } \\
\text { sided testing }\end{array}$ & $+/+$ & $+/+$ & $+/+$ & $-{ }^{c} /+$ & $-{ }^{c} /+$ \\
\hline Inspection complexity & Low & Medium & Low & High & Low \\
\hline
\end{tabular}

a By using neural network.

b By calculating attenuation coefficient.

c Except a one-sided procedure where a reflector is placed behind a test sample.

implementing optical heating with Xenon lamps (Tanimoto criterion value $87 \%$ ). Close values of the Tanimoto criterion have been achieved by using the optical and THz line-scanning procedures. A more subjective evaluation of test procedures has been performed by comparing eight parameters of test performance. From this point of view, a linescanning TNDT procedure implementing optical heating with halogen lamps has seemed to be optimal in practical applications. THz imaging is a relatively novel NDT method. It is promising in the inspection of GFRP due to high transparency of this composite toward $\mathrm{THz}$ radiation, and one may expect its performance to improve in the near future.

\section{CRediT authorship contribution statement}

A.O. Chulkov: Conceptualization, Investigation, Writing - original draft, Writing - review \& editing. A. Sommier: Investigation, Software. C. Pradere: Methodology, Validation, Resources. V.P. Vavilov: Methodology, Writing - original draft, Writing - review \& editing, Formal analysis, Project administration. A.O. Siddiqui: Resources, Writing review \& editing. Y.L.V.D. Prasad: Resources, Project administration.

\section{Declaration of competing interest}

The authors declare that they have no known competing financial interests or personal relationships that could have appeared to influence the work reported in this paper.

\section{Acknowledgement}

This study was supported by Tomsk Polytechnic University Competitiveness Enhancement Program (scientific equipment), the ASL/31/16/4020/64/0498/0043 Contract between ASL, India, and TPU, Russia (experimentation), and the Russian Scientific Foundation grant \# 17-19-01047p (data processing).

\section{Appendix A. Supplementary data}

Supplementary data to this article can be found online at https://doi. org/10.1016/j.ndteint.2020.102383.

\section{References}

[1] Almond D, Angioni S, Pickering G. Long pulse excitation thermographic non destructive evaluation. NDT E Int 2017;87:7-14.

[2] Lopez F, Ibarra-Castanedo C, de Paulo Nicolau V, Maldague X. Optimization of pulsed thermography inspection by partial least-squares regression. NDT E Int 2014;66:128-38.
[3] Ruizhen Y, Yunze H. Optically and non-optically excited thermography for composites: a review. Infrared Phys Technol 2016;75:26-50. https://doi.org/ 10.1016/j.infrared.2015.12.026.

[4] Yang B, Huang Y, Cheng L. Defect detection and evaluation of ultrasonic infrared thermography for aerospace CFRP composites. Infrared Phys Technol 2013;60: 166-73.

[5] Vavilov V. Infrared techniques for materials analysis and nondestructive testing. Infrared Methodology and Technology. Gordon \& Breach Science Publish; 1994. p. 230-309.

[6] Vavilov V, Bison P, Grinzato E. Statistical evaluation of thermographic NDT performance applied to carbon epoxy plastics. Proc. SPIE. Thermosense-XVIII 1996;2766:174-7.

[7] Saeed S, Khodayar F, Lopez F, Ibarra-Castando C, Maldague X, Vavilov VP, et al. Infrared testing of CFRP components: comparisons of approaches using the Tanimoto criterion. NDT in Canada 2015 conference 2015:1-8. https://www.ndt. net/app.NDTCanada2015.

[8] Ghiassi RS, Duan Y, Peycheva K, Maldague X. Inspection of glass fiber reinforced plastic (GFRP) using near/shortwave infrared and ultrasound/optical excitation thermography. Proc. Smart materials, structures \& NDT in aerospace Quebec 2011: 14.

[9] Ranjit S, Choi M, Kim W. Quantification of defects depth in glass fiber reinforced plastic plate by infrared lock-in thermography. J Mech Sci Technol 2016;30: 1111-8.

[10] Arora V, Mulaveesala R, Rani A, Sharma A. Digitised frequency modulated thermal wave imaging for nondestructive testing and evaluation of glass fiber reinforced polymers. Nondestr Test Eval 2019;34(1):23-32.

[11] Ciampa F, Mahmoodi P, Pinto F, Meo M. Recent advances in active infrared thermography for non-destructive testing of aerospace components. Sensors 2018; 18(609):1-37. https://doi.org/10.3390/s18020609.

[12] Tashan J, Al-Mahaidi R. Detection of cracks in concrete strengthened with CFRP systems using infrared thermography. Compos B Eng 2014;64:116-25. https://doi. org/10.1016/j.compositesb.2014.04.011.

[13] Palumbo D, Cavallo P, Galietti U. An investigation of the stepped thermography technique for defects evaluation in GFRP materials. NDT E Int 2019;102:254-63. https://doi.org/10.1016/j.ndteint.2018.12.011.

[14] Lopez F, Ibarra-Castanedo C, Nicolau P, Maldague X. Optimization of pulsed thermography inspection by partial least-squares regression. NDT E Int 2014;66: $128-38$.

[15] Rutz F, Wietzke S, Koch M. Nondestructive testing of glass-fiber reinforced polymers using Terahertz spectroscopy. Proc. ECNDT 2006;8. www.researchgate. net/publication/239922927.

[16] Chulkov A, Gaverina L, Pradere C, Batsale J-C, Vavilov V. Water detection in honeycomb composite structures using terahertz thermography. Russ J Nondestr Test 2015;51(8):520-3. https://doi.org/10.1134/\$1061830915080033.

[17] Li Z, Haigh A, Soutis C, Wang P. A review of microwave testing of glass fibrereinforced polymer composites. Nondestr Test Eval 2019;7. https://doi.org/ $10.1080 / 10589759.2019 .1605603$.

[18] Friederich F, May KH, Baccouche B, Matheis C, Bauer M, Jonuscheit J, et al. Terahertz random inspection. Photonics 2018;5(1).

[19] Rajic N. A quantitative approach to active thermographic inspection for material loss evaluation in metallic structures. Res. In NDE 2000;12:119-31.

[20] Parvataneni R. Principal component thermography for steady thermal perturbation scenarios. Clemson University. All Theses; 2009. p. 702.

[21] Winfree W, Cramer K, Zalameda J, Howell P, Burke E. Principal component analysis of thermographic data. Proceedings Thermal Infrared Applications XXXVII 2015:9485. https://doi.org/10.1117/12.2176285.

[22] Shepard S. Advances in pulsed thermography. Proc SPIE 4360 2001:510-5. https://doi.org/10.1117/12.421032. Thermosense XXIII.

[23] Balageas D, Chapuis B, Deban G, Passilly F. Improvement of the detection of defects by pulse thermography thanks to the TSR approach in the case of a smart 
composite repair patch. Quantitative InfraRed Thermography Journal 2010: 167-87. https://doi.org/10.3166/qirt.7.167-187.

[24] D'Accardi E, Palumbo D, Tamborrino R, Galietti U. Quantitative analysis of thermographic data through different algorithms. Procedia Structural Integrity 2018;8:354-67.

[25] Balageas D, Roche JM, Leroy H. Comparative assessment of thermal NDT data processing techniques for carbon fiber reinforced polymers. Mater Eval 2017;75 (8):1019-31.

[26] Layer-3 analytic operation manual. Tomsk Polytechnic University; 2016. p. 28.

[27] Vavilov VP, Maldague X. Dynamic thermal tomography: new promise in the IR thermography of solids. Proc SPIE 1992;1682:194-206.

[28] Heifetz A, Sun JG, Elmer T, Shribak D, Saboriendo B, Kozak P, et al. Pulsed Thermal tomography nondestructive evaluation advanced methods for manufacturing. In: Annual program review. Argonne National Laboratory; 2018.

[29] Sun J. Method for thermal tomography of thermal effusivity from pulsed therma imaging. US Patent No; 2006. 7365330.

[30] Sun J. Method for implementing depth deconvolution algorithm for enhanced thermal tomography 3D imaging. 2013. U.S. Patent No. 8465200.
[31] Sun J. Quantitative three-dimensional imaging of heterogeneous materials by thermal tomography. J Heat Tran 2016;138(11). https://doi.org/10.1115/ 1.4033998 .

[32] Toivanen J, Tarvainen T, Huttunen J, Savolainen T, Pulkkinen A, Orlande H, et al. Thermal tomography utilizing truncated Fourier series approximation of the heat diffusion equation. Int J Heat Mass Tran 2017;108:860-7. https://doi.org/ 10.1016/j.ijheatmasstransfer.2016.12.060.

[33] Toivanen J, Tarvainen T, Huttunen J, Kolehmainen V. Simultaneous estimation of spatially distributed thermal conductivity, heat capacity and surface heat transfer coefficient in thermal tomography. Int J Heat Mass Tran 2012;55:7958-68. https://doi.org/10.1016/j.ijheatmasstransfer.2012.08.024.

[34] Pradere C, Caumes J-P, Balageas D, Batsale J-C. Photothermal converters for quantitative 2D and 3D real-time TeraHertz imaging. QIRT J 2010;7(2):217-35. https://doi.org/10.3166/qirt.7.217-235.

[35] TeraSense TeraHertz imaging. The world's first high speed terahertz imaging camera, http://www.terasense.com. 